\title{
Battery Equalization by Fly-Back Transformers with Inductance, Capacitance and Diode Absorbing Circuits
}

\author{
Xintian Liu ${ }^{1}$, Yafei Sun ${ }^{1}$, Yao He ${ }^{1, *}$, Xinxin Zheng ${ }^{1}$, Guojian Zeng ${ }^{1}$ and Jiangfeng Zhang ${ }^{2}$ \\ 1 Intelligent Manufacturing Institute, Hefei University of Technology, 193 Tunxi Road, Hefei 230000, China; \\ xintian.liu@hfut.edu.cn (X.L.); yafei.sun2015@foxmail.com (Y.S.); xinxin.zheng@hfut.edu.cn (X.Z.); \\ guojian.zeng@hfut.edu.cn (G.Z.) \\ 2 School of Electrical and Data Engineering, University of Technology Sydney, 81 Broadway, \\ Sydney, NSW 2007, Australia; Jiangfeng.Zhang@uts.edu.au \\ * Correspondence: yao.he@hfut.edu.cn; Tel.: +86-186-5603-6882
}

Academic Editor: Hai-Wen Li

Received: 5 August 2017; Accepted: 20 September 2017; Published: 25 September 2017

\begin{abstract}
Battery equalization can increase batteries' life cycle, utilization, and reliability. Compared with battery equalization topologies based on resistance or energy storage components, the topologies based on transformers have the advantages of high balancing current and efficiency. However, the existence of switching losses will reduce the reliability and service life span of the equalization circuit. Aiming at resolving this problem, a new battery equalization topology by fly-back transformer with an absorbing circuit is proposed in this paper. Compared with other transformer-based topologies, it can decrease switching losses because the voltage/current spike is solved by the absorbing circuit which is composed of inductance, capacitance and diode (LCD), and it can also maintain a high balancing current of about $1.8 \mathrm{~A}$ and high efficiency of about $89 \%$, while the balancing current and efficiency of other topologies were usually $1.725 \mathrm{~A} / 1.5 \mathrm{~A}$ and $80 \% / 80.4 \%$. The working principle of the balancing topology and the process of soft switching are analyzed and calculated in the frequency domain. Due to the addition of the LCD absorbing circuit, soft switching can be realized to reduce the switching losses while the high equalization speed and efficiency are still maintained. The corresponding control strategy of the balancing topology is also proposed and the timely balancing is achieved. The theoretical analysis is verified by simulation and experimental results.
\end{abstract}

Keywords: battery equalization; fly-back transformer; absorbing circuit; soft switching; frequency domain

\section{Introduction}

Nowadays, electric vehicles (EV) are experiencing rapid development due to their low-carbon nature when renewable energy is adopted for charging [1,2]. However, the battery packs of EVs contain a number of battery cells connected in series, whose performances are often different [3-5]. If the differences among battery cells are ignored in battery pack control, then some issues might appear, such as overcharging or overdischarging, which can reduce the life cycle of the battery and sometimes even risk explosions [6]. To avoid these problems, balancing of electric vehicle batteries has drawn more attention due to its importance to improve the life cycle and energy utilization of the batteries [7-9].

Presently, two main ways to balance batteries are proposed: passive and active [10]. Passive balancing methods dissipate the excess energy in the form of heat through shunt resistors [11], while active balancing methods transfer the electrical charge from the cells with higher energy content 
to the cells with lower energy content [12]. A review of the literature shows that a lot of research has been carried out in the field of active balancing. Reference [13] proposed two new buck-boost neutral-point-clamped (NPC) inverters with simple capacitive-voltage-balancing capability. Both inverters were demonstrated to exhibit a doubling of voltage gain, with one of them also shown to produce a better output waveform quality. In [14], energy storage inductors were applied in a balancing circuit and their number was less than that of the switches. The topology was simple and easy to control. Different battery balancing circuit topologies are reported depending on the energy storage component, such as a novel voltage equalizer based on the two-phase switched capacitor technique [15], single switched capacitor (SSC) cell balancing [16], an equalization system based on a quasi-resonant switched-capacitor converter [17] and a flying-capacitor-based chopper circuit for DC capacitor voltage equalization in diode-clamped multilevel inverters [18]. Topologies based on transformers are also widely discussed due to their high balancing current and efficiency. For example, the current of each battery cell of a serially connected battery stack was controlled according to each cells' capacity in [19]. A circuit for balancing with one small transformer and N+3 bilateral switches was presented in [20]. A cell-to-cell charge equalization converter using a multi-winding transformer was discussed in [21], which achieved direct cell-to-cell charge transportation by buck-boost and fly-back operation. Though topologies based on transformers have the advantages of high balancing current and efficiency, voltage/current spikes still exist, which will lead to switching losses. For example, [22] proposed a novel inductor-based layered bidirectional equalizer, and [23] used a fly-back converter to implement multiple filling valley balancing. Their equalization speeds were all fast but with high switching losses, thus they have a high requirement for switches. An active charge equalization technique based on a dc/dc converter topology was proposed in [24], where cell balancing of batteries in a stack with fast speed was achieved but it still cannot avoid switching losses. Reference [25] proposed a new bidirectional cell-to-cell active equalization method with a multi-winding transformer, which had the advantages of not only fast speed but also high efficiency, however, its switching losses were still high. Reference [26] presented a simple circuit for balancing series-connected battery cells, which was composed of one low-voltage metal-oxide-semiconductor field-effect transistor (MOSFET) for each cell and a symmetrical multi-winding transformer for a group of cells, whose control was simple and reliable, however, it had voltage/current spikes without soft switching.

To avoid the switching losses, which are caused by the voltage/current spike problem, absorption networks are proposed in the literature. The block circuit composed of resistance, capacitance and diode ( $R C D$ ) is used in the converter to effectively suppress the voltage spike problem, however, the energy absorbed by the power tube is dissipated as heat by the electric resistance, which leads to a reduction of the topology efficiency [27]. Compared with the RCD clamp circuit, lossless absorption networka composed of inductance, capacitance and diode (LCD) can not only return the energy to the power supply without resistance heat loss, but also realize the soft switching power transistor in the absorption peak voltage at the same time, therefore, improving the efficiency and reliability of the converter [28].

Targeting at reducing switching losses, this paper proposes a new equalization scheme which adopts an equalization topology based on a transformer with single input and multiple outputs. The peak voltage can be absorbed by the LCD loop and the soft switching can be achieved by the resonant circuit. The balancing topology analysis and power switch mode circuit control to achieve soft switching are introduced in Section 2. The operation of energy transfer is given in Section 3. The equilibrium control strategy formulation is proposed in Section 4, and the proposed equalization method is verified by Matlab/Simulink (8.0.0.783, Mathworks, Natick, MA, USA) simulation and an experimental platform in Section 5. Conclusions are then made in Section 6. 


\section{Balancing Circuit Based on Transformer}

\subsection{Analysis of Topology}

Though balancing circuit topologies based on transformers are widely studied because of their high balancing currents, the leakage inductance of the transformer may cause the voltage/current spike problem, which leads to high switching losses. Therefore, a LCD lossless absorption network is added in this paper to reduce switching losses. The topology of the equalization circuit is shown in Figure 1, where $U_{b a t, n}$ is the voltage of the battery in cell $n, U$ is the sum of the voltage of the battery pack, $S_{n}$ is the power tube of section $n$ of the transformer, and $L_{n 1}, C_{n 1}, D_{n 1}, D_{n 2}$ form the corresponding LCD absorption network. There are $N$ batteries, the transformer has $N$ secondary sides and one primary side, with each turns ratio equal to $1: N$.

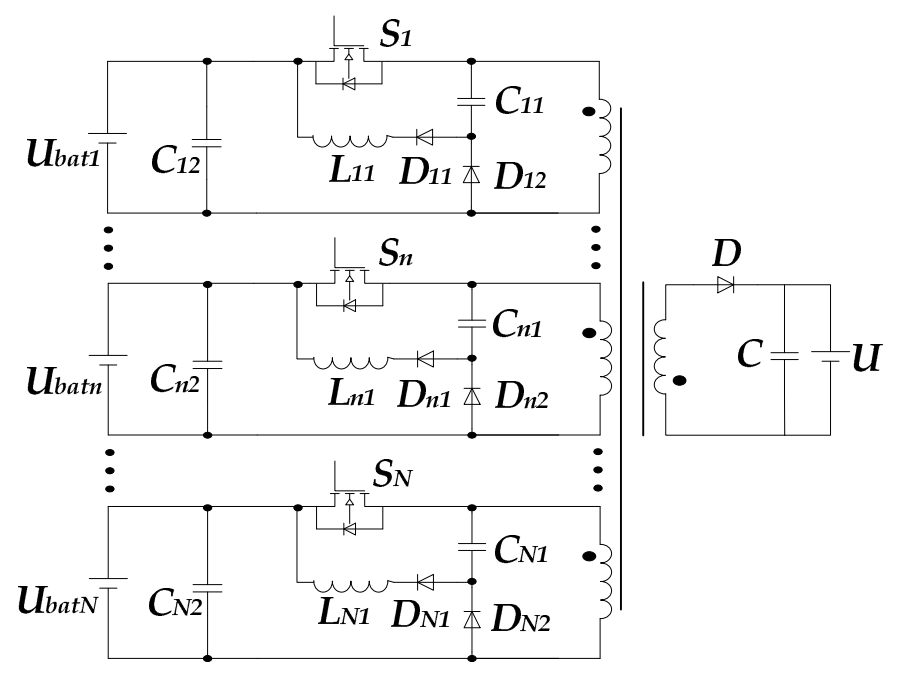

Figure 1. The equalization circuit topology.

\subsection{Analysis of Switching Mode}

In order to simplify the analysis, each secondary side is separated, which is shown in Figure 2.

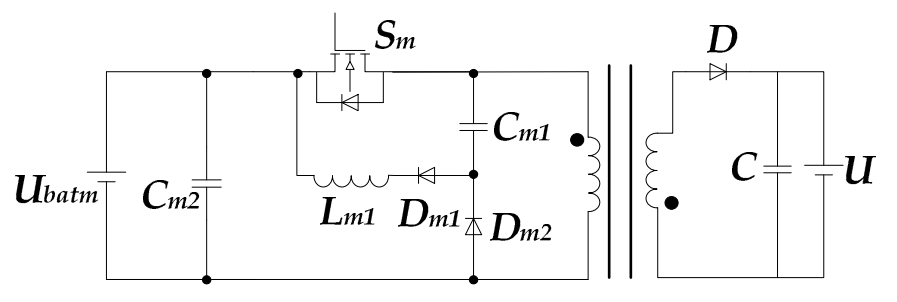

Figure 2. Single circuit topology.

Assume that cell $m$ of the batteries has the largest state of charge (SOC), that is, under the premise that $S_{m}$ conducts, $U_{b a t, m}$ is applied to the transformer, which leads energy from section $m$ to flowing to the transformer. When $S_{m}$ is turned off, the energy of the transformer flows to the whole battery pack and returns back to cell $m$. Due to the existence of the LCD absorption circuit, the voltage and current spikes are avoided.

The current direction of each modality is shown in Figure 3. In order to facilitate modal analysis, the transformer is made equivalent to an inductance $L_{m m}$ [29]. Its critical voltage/current waveforms are shown as Figure 4: the driver signal of $S_{m}\left(u_{g m}\right)$, current through $S_{m}\left(i_{S m}\right)$, drain-source voltage of $S_{m}\left(u_{d s m}\right)$, voltage of $C_{m 1}\left(u_{C m 1}\right)$, current through $L_{m 1}\left(i_{L m 1}\right)$, and current through transformer $\left(i_{m m}\right)$. 


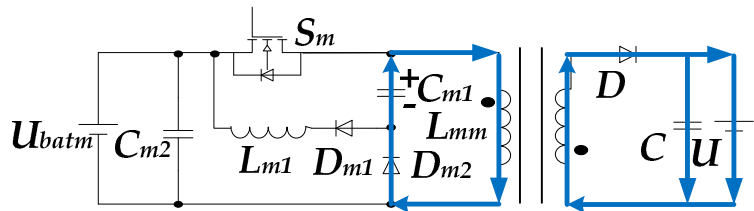

(a)

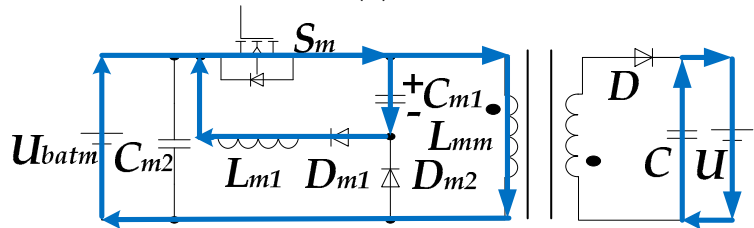

(c)

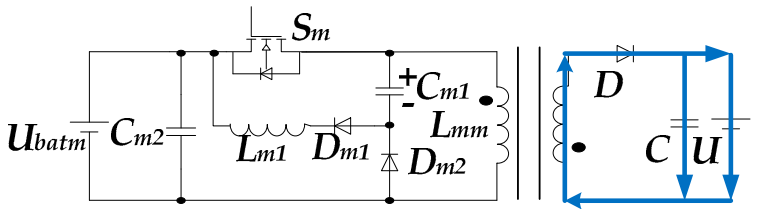

(b)

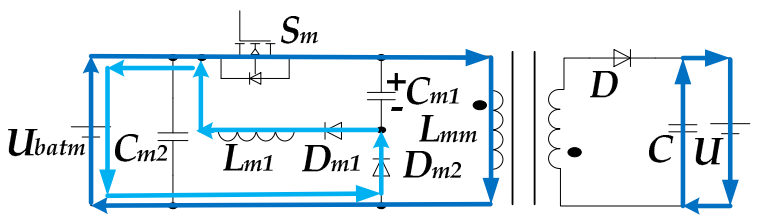

(d)

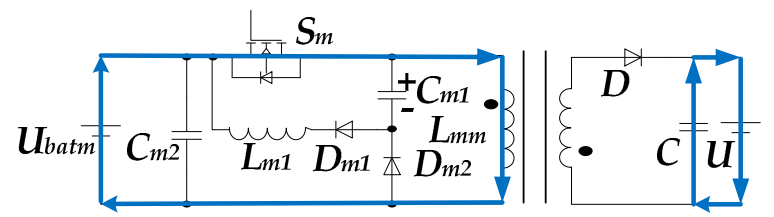

(e)

Figure 3. The current direction: (a) Modality $1\left(t_{0}-t_{1}\right)$; (b) Modality $2\left(t_{1}-t_{2}\right)$; (c) Modality $3\left(t_{2}-t_{3}\right)$; (d) Modality $4\left(t_{3}-t_{4}\right)$; (e) Modality $5\left(t_{4}-t_{5}\right)$.

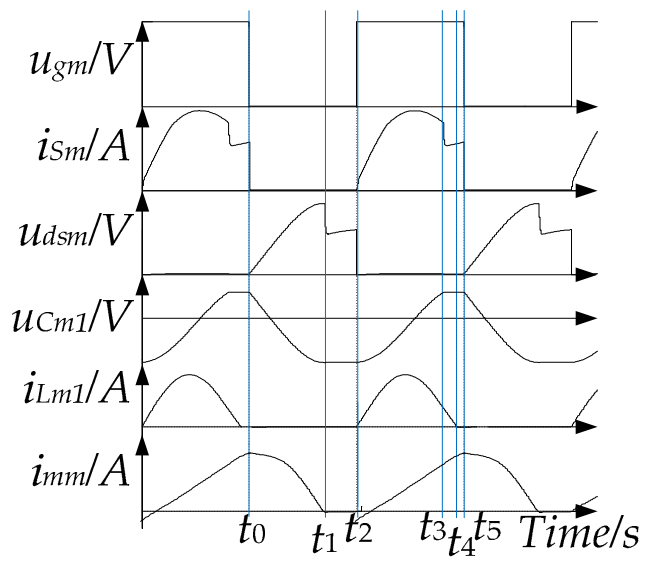

Figure 4. Key waveforms.

According to the waveforms shown in Figure 4, the analysis of switching mode is shown as follows:

1. Modality $1\left(t_{0}-t_{1}\right)$

At the time instant $t_{0}, S_{m}$ turns off. Because of the previously stored energy in the transformer which is made equivalent to an inductance $L_{m m}$, the direction of $i_{m m}$ cannot be mutated; $D_{m 2}$ is on, formulating continuous current flow path; $C_{m 1}$ and $L_{m m}$ resonate until $i_{m m}$ decreases to 0 . At the beginning, $u_{C m 1}$ is positive if the positive direction of $u_{C m 1}$ is as in Figure 3 . The initial energy of the resonant circuit is given by Equation (1):

$$
E_{L m m, C m 1}=\frac{1}{2} C_{m 1} u_{C m 1}{ }^{2}\left(t_{0}\right)+\frac{1}{2} L_{m m} i_{m m}^{2}\left(t_{0}\right)
$$

At the end of the previous mode, $u_{C m 1}$ is clamped at $U_{b a t, m}$, so $u_{C m 1}\left(t_{0}\right)$ in the equation is equal to $U_{b a t, m}$. After $C_{m 1}$ is added to the resonant circuit, $u_{C m 1}$ is resonated to zero, and then decreases from 
zero to negative values, which makes the voltage of $C_{m 1}$ becomes negative. $L_{m m}$ is discharged, and $i_{m m}$ is gradually reduced with the direction shown in Figure 3a.

Assume that the capacitance resonance voltage is defined as:

$$
u_{C m 1}(t)=U_{b a t m}-U_{C m 1} \sin \omega_{1}\left(t-t_{0}\right)
$$

where $u_{C m 1}$ is the resonance voltage of $C_{m 1}, \omega_{1}$ is the resonance frequency with the following expression:

$$
\omega_{1}=1 / \sqrt{C_{m 1} L_{m m}}
$$

The resonance current can be written as follows:

$$
i_{m m}(t)=C_{m 1} U_{C m 1} \omega_{1} \cos \omega_{1}\left(t-t_{0}\right)
$$

Ignoring line losses and following from the conservation law of energy, we can simplify the resonance voltage $u_{\mathrm{Cm} 1}$ as Equation (5):

$$
U_{C m 1}=\sqrt{2 E_{L m m, C m 1} / C_{m 1}}
$$

The drain source voltage of power tube is $u_{d s m}$, which is calculated as:

$$
u_{d s m}(t)=\sqrt{2 E_{L m m, C m 1} / C_{m 1}} \sin \omega_{1}\left(t-t_{0}\right)
$$

It can be seen from Equation (6) that $u_{d s m}$ gradually increases from zero, that is, the power tube achieves zero voltage turn off. During this modality, the energy of transformer flows to $C_{m 1}, C, U$.

2. Modality $2\left(t_{1}-t_{2}\right)$

During this time period $\left(t_{1}-t_{2}\right), S_{m}$ is off, $i_{m m}$ decreases to 0 , and $u_{C m 1}$ reaches a minimum from a positive initial to a negative value. $D_{m 1}$ and $D_{m 2}$ are off, $u_{d s m}$ jumps to a smaller value, and the energy of the transformer still flows to $C$ and $U$.

3. Modality $3\left(t_{2}-t_{3}\right)$

At time $t_{2}, S_{m}$ turns on, $D_{m 1}$ is also on, and $D_{m 2}$ is off. $C_{m 1}$ and $L_{m 1}$ participate in the resonance, and $C_{m 1}$ is discharged. $u_{C m 1}$ increases from minimum negative to maximum positive. $i_{L m 1}$ increases first, then decreases. When $u_{C m 1}$ increases to $U_{b a t, m}, D_{m 2}$ is on, and $u_{C m 1}$ is clamped at $U_{b a t, m}$. During this modality, $i_{m m}$ increases gradually from 0 , the energy flows from the battery to the transformer.

The current flowing through power tube $S_{m}$ is given by:

$$
i_{S m}(t)=i_{L m 1}\left(t_{2}\right)+I_{L m 1, C m 1} \sin \omega_{2}\left(t-t_{2}\right)+i_{m m}(t)
$$

where $I_{L m 1, C m 1}$ is the peak value of the resonant current and $\omega_{2}$ is the resonance frequency which is given as follows:

$$
\omega_{2}=1 / \sqrt{C_{m 1} L_{m 1}}
$$

$L_{m m}$ does not participate in the resonance, so $i_{m m}$ increases linearly and satisfies the following relation:

$$
i_{m m}(t)=i_{m m}\left(t_{3}\right)+\frac{U_{b a t} t}{L_{m m}}
$$

Since $L_{m 1}$ and $L_{m m}$ are 0 at the initial time $t_{2}$, we can easily know that:

$$
i_{S m}(t)=I_{L m 1, C m 1} \sin \omega_{2}\left(t-t_{2}\right)
$$


From Equation (10), it is observed that $i_{S m}$ gradually increases from zero after the moment $t_{2}$, that is, the power tube achieves zero current turn on.

4. Modality $4\left(t_{3}-t_{4}\right)$

At time interval $\left(t_{3}-t_{4}\right), S_{m}, D_{m 1}$, and $D_{m 2}$ are on. $u_{C m 1}$ is embedded in $U_{b a t, m}, i_{L m 1}$ still decreases until zero through the battery, and $i_{S m}$ drops down suddenly and then continues to grow.

5. Modality $5\left(t_{4}-t_{5}\right)$

During this time interval, $i_{L m 1}$ decreases to $0, D_{m 1}$ and $D_{m 2}$ are off, $i_{m m}$ continues to increase until it reaches the initial value of modality 1.

\section{Operation of Energy Transfer}

The energy transfer process of the circuit is that energy is transferred from the cell which had the highest SOC to the transformer; then part of the energy is transferred from the transformer to the whole battery pack through the primary side, and part of the energy in transformer flows back to the cell to be discharged because of the addition of LCD absorbing circuit. In order to analyze the working principle of the circuit in details, the circuit is analyzed and calculated in frequency domain.

When the switch is turned on, energy is transferred from the battery $m$ to the transformer. It can be described by the equivalent model as shown in Figure $5 \mathrm{a}$, or the frequency domain equivalent model in Figure $5 \mathrm{~b}$ as $i_{m m}$ and $i_{L m}$ are 0 at the beginning.

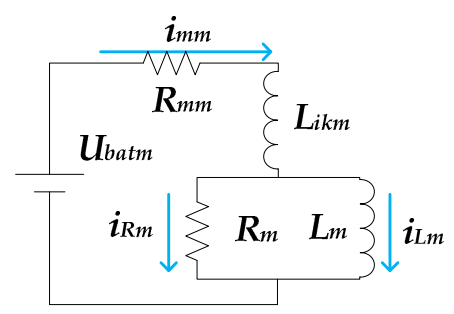

(a)

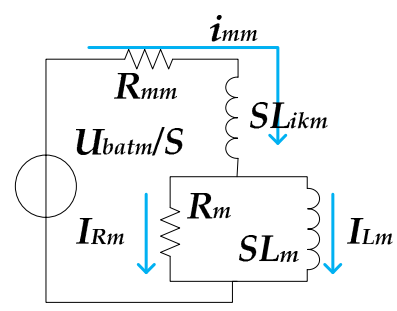

(b)

Figure 5. The equivalent model of secondary side when the switch is on: (a) Time domain; (b) Frequency domain.

In Figure $5, L_{i k m}, R_{m}$, and $L_{m}$ are the transformer's leakage inductance, excitation resistance, and excitation inductance, respectively. Among them, the excitation resistance $R_{m}$ and leakage inductance $L_{i k m}$ are used to describe the loss of the charging process on the secondary side, which makes the model approximate better the actual working condition of the transformer; Excitation inductance $L_{m}$ is used to describe the energy loss caused by the non-ideal magnetic of the transformer coupling, such as the air gap of the transformer. The direction in the circuit is shown in Figure 5. According to Kirchhoff's voltage law, we can list frequency domain equations as Equation (11). From (11), we can get the current expression as Equation (12):

$$
\left\{\begin{array}{l}
\frac{U_{\text {batm }}}{S}-\left(R_{m m}+S L_{i k m}\right) I_{m m}-R_{m} I_{R_{m}}=0 \\
R_{m} I_{R_{m}}=S L_{m} I_{L_{m}} \\
I_{m m}=I_{R_{m}}+I_{L_{m}}
\end{array}\right.
$$




$$
\left\{\begin{array}{l}
I_{L_{m}}=\frac{a_{1}}{b_{1} S^{3}+c_{1} S^{2}+d_{1} S} \\
I_{R_{m}}=\frac{a_{2} S}{b_{2} S^{3}+c_{2} S^{2}+d_{2} S} \\
I_{m m}=\frac{a_{3} S+b_{3}}{c_{3} S^{3}+d_{3} S^{2}+e_{3} S} \\
a_{1}=b_{3}=R_{m} U_{b a t m} \\
b_{1}=b_{2}=c_{3}=L_{m} L_{i k m} \\
c_{1}=c_{2}=d_{3}=L_{m} R_{m}+L_{m} R_{m m}+L_{i k m} R_{m} \\
d_{1}=d_{2}=e_{3}=R_{m} R_{m m} \\
a_{2}=a_{3}=L_{m} U_{b a t m}
\end{array}\right.
$$

Assuming that $U_{b a t, m}$ is $4 \mathrm{~V}, R_{m}$ is $10^{5} \Omega, R_{m m}$ is $10^{-3} \Omega, L_{i k m}$ is $10^{-4} \mathrm{H}, L_{m}$ is $10^{-3} \mathrm{H}$, then we apply inverse Laplace transformation function in MATLAB to obtain the current waveforms as Figure 6 . Through the above waveforms, we can see that the current of the transformer increases almost linearly, and the energy flows are as:

$$
\left\{\begin{array}{l}
E_{R_{m m}}=\int i_{m m}^{2} R_{m m} d t \\
E_{L_{i k m}}=\frac{1}{2} L_{i k m} i_{m m}^{2} \\
E_{L_{m}}=\frac{1}{2} L_{m} i_{L_{m}}^{2} \\
E_{R_{m}}=\int i_{R_{m}}^{2} R_{m} d t \\
E_{b a t, m, o}=\int U_{b a t m} i_{m m} d t
\end{array}\right.
$$

where $E_{R m m}$ is the loss of the circuit resistance, $E_{L i k m}$ is the loss of leakage inductance, $E_{L m}$ is the actual energy absorption of the transformer, $E$ is the energy loss of excitation resistance, $E_{b a t, m, o}$ is the energy released by the $m$-th battery.

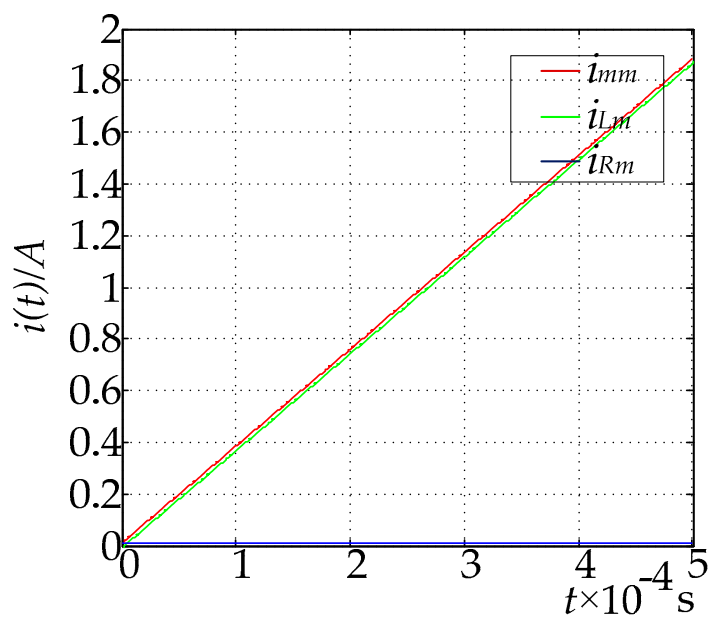

Figure 6. Current waveforms of Figure 5.

When the switch is turned off, the previously stored energy in the transformer is transferred to $C_{m 1}$ and the whole battery pack. The energy transferred to $C_{m 1}$ is analyzed as follow. Figure $7 \mathrm{a}$ is the secondary side of the transformer equivalent circuit in time domain, Figure $7 \mathrm{~b}$ is its frequency domain equivalent circuit. 


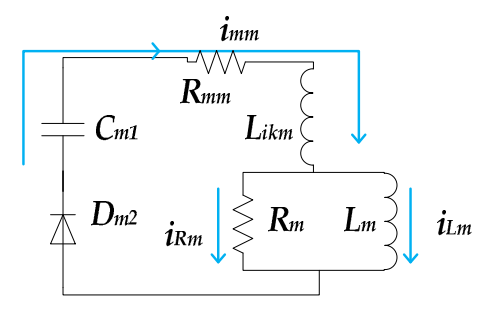

(a)

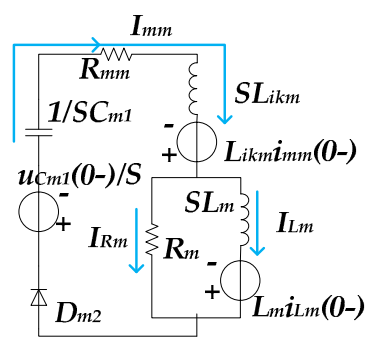

(b)

Figure 7. The equivalent model of secondary side when the switch is off: (a) Time domain; (b) Frequency domain.

According to Kirchhoff's voltage law, we can list frequency domain equations as in (14). From Equation (14), we can get the current expression as Equation (15):

$$
\begin{gathered}
\left\{\begin{array}{l}
\quad \frac{u_{C_{m 1}}\left(0_{-}\right)}{S}+I_{m m}\left(\frac{1}{S C_{m 1}}+R_{m m}+S L_{i k m}\right)-L_{i k m} i_{m m}\left(0_{-}\right)+I_{R_{m}} R_{m}=0 \\
I_{R_{m}} R_{m}=I_{L_{m}} S L_{m}-L_{m} i_{L_{m}}\left(0_{-}\right) \\
I_{m m}=I_{R_{m}}+I_{L_{m}}
\end{array}\right. \\
\left\{\begin{array}{l}
I_{L_{m}}=\frac{a_{1} S^{2}+b_{1} S+c_{1}}{d_{1} S^{4}+e_{1} S^{3}+f_{1} S^{2}+g_{1} S} \\
I_{R_{m}}=\frac{a_{2} S^{2}+b_{2} S+c_{2}}{d_{2} S^{3}+e_{2} S^{2}+f_{2} S+g_{2}} \\
I_{m m}=\frac{a_{3} S^{3}+b_{3} S^{2}+c_{3} S+d_{3}}{e_{3} S^{4}+f_{3} S^{3}+g_{3} S^{2}+h_{3} S} \\
a_{1}=C_{m 1} L_{i k m} R_{m}\left(i_{m m}\left(0_{-}\right)-i_{L m}\left(0_{-}\right)\right) \\
b_{1}=-C_{m 1} R_{m}\left(R_{m m} i_{L m}\left(0_{-}\right)+u_{C m 1}\left(0_{-}\right)\right) \\
c_{1}=d_{3}=-R_{m} i_{L m}\left(0_{-}\right) \\
d_{1}=d_{2}=e_{3}=L_{m} C_{m 1} L_{i k m} \\
e_{1}=e_{2}=f_{3}=C_{m 1}\left(L_{m} R_{m m}+R_{m} L_{i k m}+L_{m} R_{m}\right) \\
f_{1}=f_{2}=g_{3}=L_{m}+C_{m 1} R_{m} R_{m m} \\
g_{1}=g_{2}=h_{3}=R_{m} \\
a_{2}=a_{3}=L_{m} C_{m 1} L_{i k m}\left(i_{m m}\left(0_{-}\right)-i_{L m}\left(0_{-}\right)\right) \\
b_{2}=-L_{m} C_{m 1}\left(R_{m m} i_{L m}\left(0_{-}\right)+u_{C m 1}\left(0_{-}\right)\right) \\
c_{2}=-L_{m} i_{L m}\left(0_{-}\right) \\
b_{3}=C_{m 1} L_{i k m} R_{m}\left(i_{m m}\left(0_{-}\right)-i_{L m}\left(0_{-}\right)\right)-L_{m} C_{m 1}\left(R_{m m} i_{L m}\left(0_{-}\right)+u_{C m 1}\left(0_{-}\right)\right) \\
c_{3}=-C_{m 1} R_{m}\left(R_{m m} i_{L m}\left(0_{-}\right)+u_{C m 1}\left(0_{-}\right)\right)-L_{m} i_{L m}\left(0_{-}\right)
\end{array}\right.
\end{gathered}
$$

$U_{C m 1}$ is calculated from $I_{m m}$ as follows:

$$
U_{C_{m 1}}=\frac{u_{c_{m 1}}\left(0_{-}\right)}{S}+\frac{I_{m m}}{S C_{m 1}}
$$

Assuming that $u_{\mathrm{Cm} 1}\left(0_{-}\right)$is $-4 \mathrm{~V}, i_{m m}\left(0_{-}\right)$is $1.875 \mathrm{~A}, i_{\mathrm{Lm}}\left(0_{-}\right)$is $1.87496 \mathrm{~A}$, Similarly, the waveforms can be obtained as follows: Figure 8 shows that the current of the transformer decreases almost as a sinusoidal function, and energy flows are characterized in (17), where $E_{R m m}$ is the loss of the circuit resistance, $E_{L i k m}$ is the loss of leakage inductance, $E_{L m}$ is the actual release energy of the transformer, $E_{R m}$ is the loss of excitation resistance, and $E_{C m 1}$ is the energy absorbed by the capacitance $C_{m 1}$. 


$$
\left\{\begin{array}{l}
E_{R_{m m}}=\int i_{m m}^{2} R_{m m} d t \\
E_{L_{i k m}}=\frac{1}{2} L_{i k m} i_{m m}^{2}-\frac{1}{2} L_{i k m} i_{m m}^{2}\left(0_{-}\right) \\
E_{L_{m}}=\frac{1}{2} L_{m} i_{L_{m}}^{2}-\frac{1}{2} L_{m} i_{L_{m}}^{2}\left(0_{-}\right) \\
E_{R_{m}}=\int i_{R_{m}}^{2} R_{m} d t \\
E_{C_{m 1}}=\frac{1}{2} C_{m 1} u_{C_{m 1}}^{2}-\frac{1}{2} C_{m 1} u_{C_{m 1}}^{2}\left(0_{-}\right)
\end{array}\right.
$$

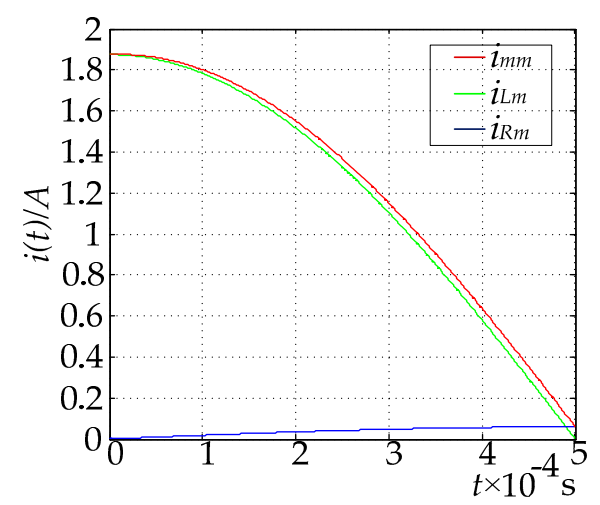

Figure 8. Current waveforms of Figure 7.

For the primary side of the transformer, when the switch is off, part of the energy stored in transformer flows to the battery pack and its equivalent circuit is shown in Figure 9.

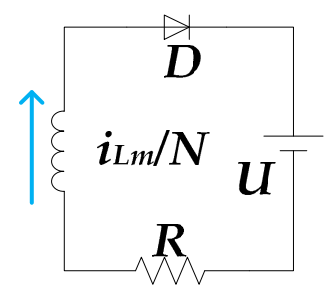

Figure 9. The equivalent model of primary side when the switch is off.

In Figure 9, $N$ is the number of batteries, and $R$ is the circuit resistance. The energy absorbed by the battery pack is shown as Equation (18):

$$
E_{U}=\frac{1}{2} L_{m} i_{L_{m}}{ }^{2}-\int\left(\frac{i_{L m}}{N}\right)^{2} R d t
$$

When the switch is on, the energy transferred from the transformer to $C_{m 1}$ before flows to $L_{m 1}$ by resonance and then to the cell $\mathrm{m}$. This circuit of feedback is analyzed as follow.

Firstly, $C_{m 1}$ and $L_{m 1}$ are resonant. The equivalent circuit is shown in Figure 10a. Energy flows from $C_{m 1}$ to $L_{m 1}$ and then from $L_{m 1}$ to $C_{m 1}$, but when the $C_{m 1}$ reaches the battery voltage, the current flow changes to Figure 10b. The feedback energy absorbed by the battery $m$ is as follows:

$$
E_{b a t, m, i}=\frac{1}{2} C_{m 1}\left(u_{C_{m 1}}(2)-u_{C_{m 1}}(1)\right)^{2}
$$




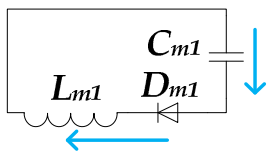

(a)

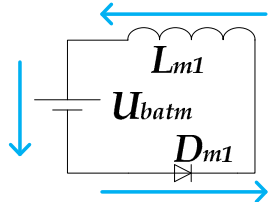

(b)

Figure 10. The equivalent model of energy feedback when the switch is on: (a) Current continuous; (b) Feedback.

According to Equations (14), (20), and (21), the energy transfer efficiency is calculated as:

$$
\eta=\frac{E_{U}}{E_{b a t, m, o}-E_{b a t, m, i}} * 100 \%
$$

\section{Control Strategy}

To realize the equalization function of the topology, the control strategy is indispensable. The balance control flow chart is shown in Figure 11.

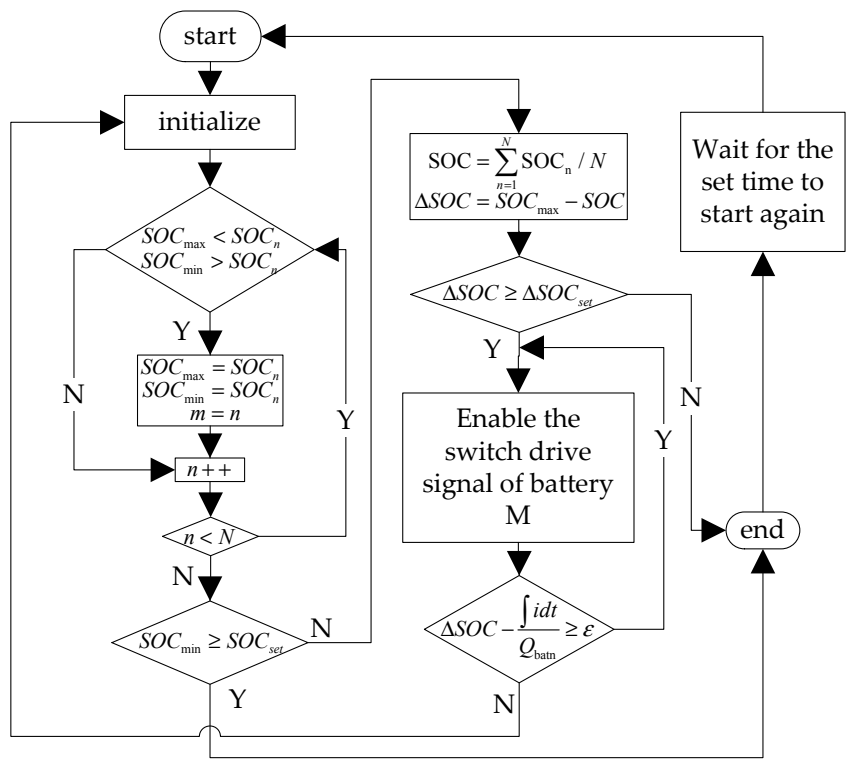

Figure 11. The balance control flow chart.

In charging and discharging process of the battery pack, the SOC of the battery cell is estimated by the Battery Management System (BMS), and here we use the SOC as the balance control parameter.

During the initialization process, the highest $S O C\left(S O C_{\max }\right)$ and the lowest $S O C\left(S O C_{\min }\right)$ are found by the bubble method [30]. If $S O C_{\min }$ is less than preset $S O C$ for starting balancing $\left(S O C_{\text {set }}\right)$, the iteration is continued, otherwise, the iteration is finished and restarted after a preset time.

$\triangle S O C$ is defined as:

$$
\triangle S O C=S O C_{\max }-\sum_{n=1}^{N} S O C_{n} / N
$$

If $\triangle S O C$ is less than preset $\triangle S O C$ for starting balancing $\left(\triangle S O C_{\text {set }}\right)$, the iteration is continued, otherwise, the iteration is finished and restarted after a preset time. If the iteration is still continued, 
the driver signal of power tube $S_{m}$ is enabled. The energy in battery $m$ flows to the transformer. In this process, the reduced amount of SOC of battery $m$ is denoted by $\triangle S O C_{m}{ }^{\prime}$ and calculated as follows:

$$
\Delta S O C^{\prime}{ }_{m}=\frac{\int i d t}{C_{b a t, m}}
$$

where $C_{\text {bat }}$ is the total capacity of battery, $i$ is the current flowing through battery. We use the outlet of positive electrode of battery as the positive current direction. When the difference between $\triangle S O C^{\prime}$ and $\triangle S O C$ is less than a number greater than $0(\varepsilon)$, the drive signal of corresponding power tube is set to low, then the iteration is restarted and reinitialized.

\section{Simulation and Experimental Verification}

In order to verify the practicability of this topology, MATLAB/Simulink is applied to build the simulation model of the balanced circuit. The parameters of the components are as follows: $C_{n 1}$ is $40 \mu \mathrm{F}, C_{n 2}$ is $3 \mathrm{mF}, L_{n 1}$ is $1 \mu \mathrm{H}$, and the leakage inductance $L_{i k m}$ is $0.7 \mu \mathrm{H}$. The power tube and diode are all ideal devices. The battery is lithium-ion, whose nominal voltage, rated fully charged voltage and rated capacity are $3.7 \mathrm{~V}, 4.2 \mathrm{~V}$ and $5 \mathrm{Ah}$, respectively. The initial SOC of each battery is $10 \%, 12 \%$, and $15 \%$. The charging current is $10 \mathrm{~A}$. The simulation waveforms of the balancing branch which has the highest SOC are shown as Figure 12. From the $i_{S m}$ and $u_{d s m}$ waveforms, we can conclude that the power tube achieves zero voltage turn off and zero current turn on.

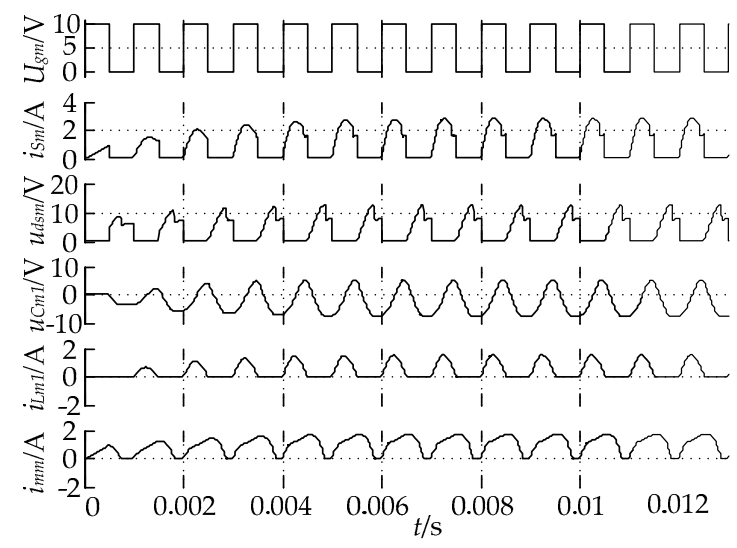

Figure 12. Simulation waveforms of voltage and current.

The simulation waveforms of each cell's voltage and SOC are shown in Figure 13. It can be observed that the differences of SOC and voltage always exist without equalization. In Figure 13a, SOCs increase from $10 \%, 12 \%$, and $15 \%$ to $93.4 \%, 95.4 \%$ and $98.4 \%$, respectively. Voltages increase from 3.607, 3.633, and 3.678 V to 3.987, 4.031, and 4.186 V, respectively. In Figure 13b, the voltages are concentrated suddenly at $800 \mathrm{~s}$ since the balancing is finished. SOCs and voltages are concentrated to $95 \%$ and $4.037 \mathrm{~V}$ at the end with the addition of equalization.

The experimental platform is built on the basis of the simulation as Figure 14. The main control chip is MC9S12XEG128, the voltage, current and temperature of the battery are collected and managed by A/D conversion interface. The batteries are Lithium-Ion with nominal voltage and rated capacity are $3.7 \mathrm{~V}$ and $10 \mathrm{Ah}$. The initial SOC of each battery is $72 \%, 73 \%$, and $75 \%$. The charging current is $5 \mathrm{~A}$. The experimental waveforms are shown as Figure 15. 

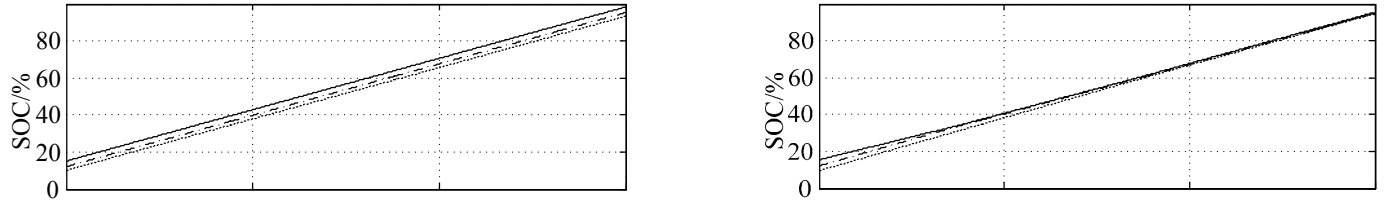

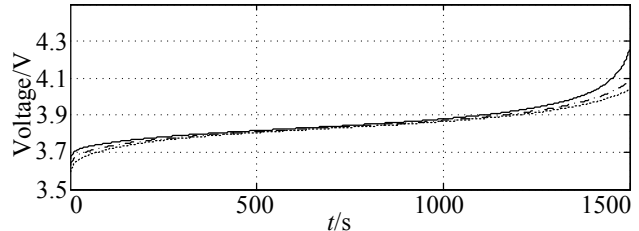

(a)

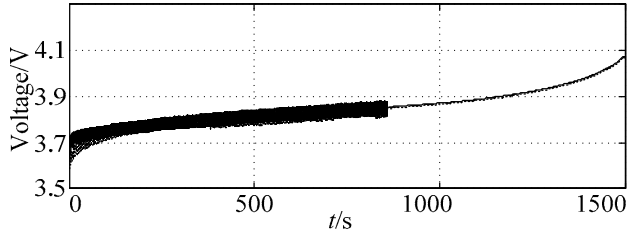

(b)

Figure 13. Simulation waveforms of each cell's voltage and SOC (a) Without equalization; (b) With equalization.

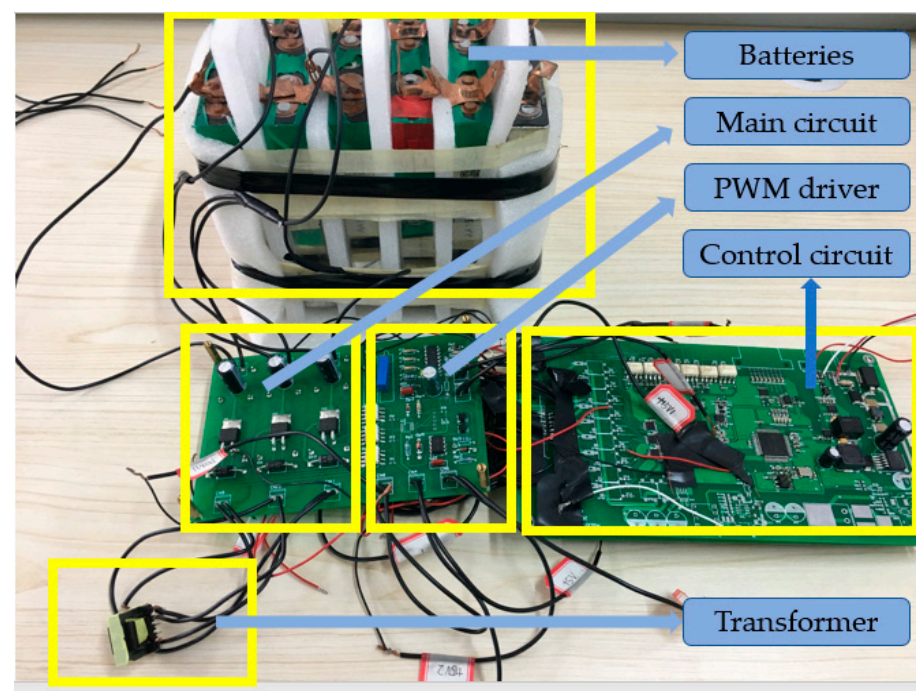

Figure 14. The experimental platform.

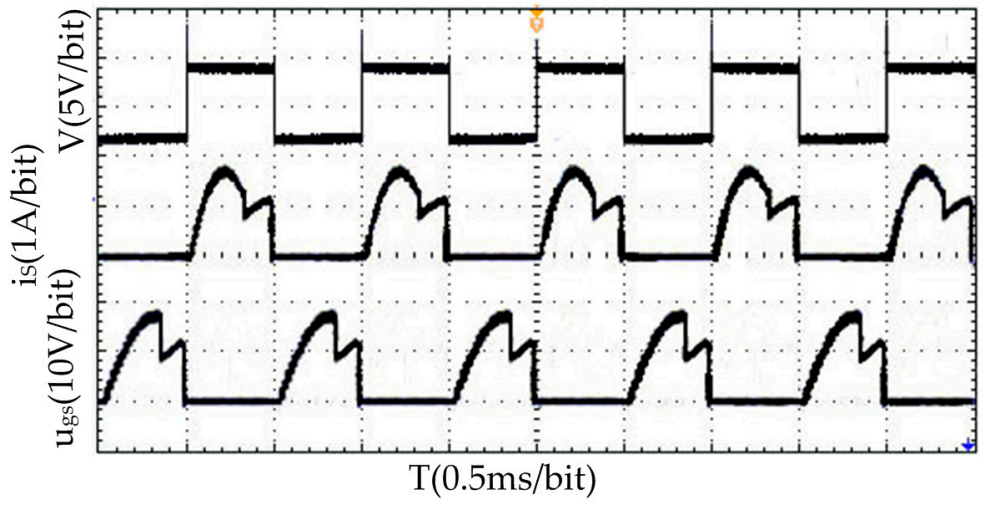

Figure 15. Experimental waveforms.

In Figure 15, it is obvious that balancing current is about $1.8 \mathrm{~A}$ and the switch can achieve zero voltage turn off and zero current turn on, so that switching losses will be reduced. The drain voltage and $V_{D S Q 1}$ waveforms of $[25,31]$ are shown in Figure 16, from which we can see that they cannot realize soft switching. 


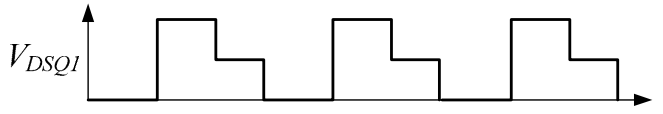

(a)

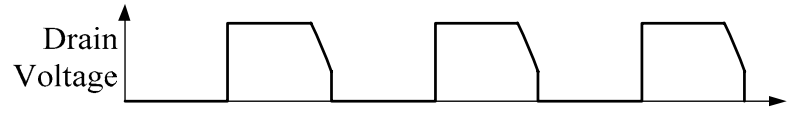

(b)

Figure 16. (a) $V_{D S Q 1}$ waveform of [25]; (b) The drain voltage waveform of [31].

Figure 17 shows the SOC and voltage distributions of each cell during the charging, and the figure is obtained through plotting measured experimental data by software tools OriginPro (8.6, OriginLab, Northampton, UK) and Visio (14.0.7188.5002, Microsoft, Washington, DC, USA). In Figure 17a, SOCs increase from $72 \%, 73 \%$, and $75 \%$ to $88.7 \%, 89.7 \%$ and $91.7 \%$, respectively. Voltages increase from $3.777,3.779$, and $3.783 \mathrm{~V}$ to 3.939, 3.951, and $3.972 \mathrm{~V}$, respectively. In Figure 17b, SOC and voltage are concentrated to $89 \%$ and $3.951 \mathrm{~V}$ with the addition of equalization.

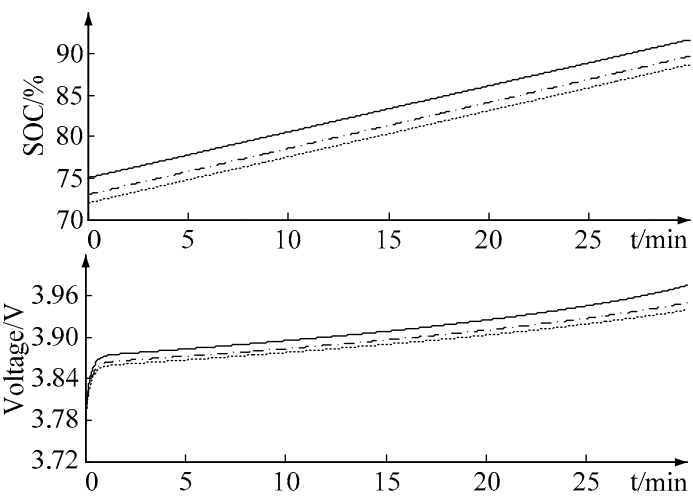

(a)

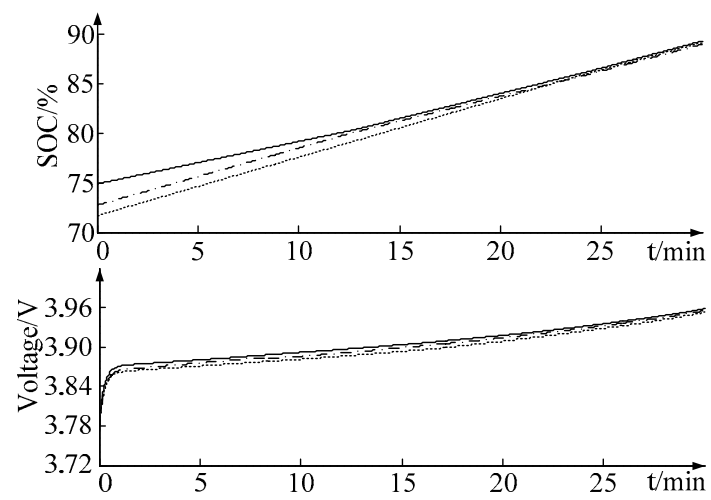

(b)

Figure 17. Voltage of each monomer battery during the charging: (a) Without equalization; (b) With equalization.

The experimental data is shown in Table 1. It is obviously that SOC and voltage are both scattered without equalization, while they converge together after the balance control.

Table 1. Data of the experiment.

\begin{tabular}{ccccc}
\hline Conditions & Parameters & Cell 1 & Cell 2 & Cell 3 \\
\hline \multirow{5}{*}{ Without Equalization } & Initial SOC (\%) & 72 & 73 & 75 \\
& SOC at 20 min (\%) & 83.3 & 84.3 & 86.3 \\
& SOC at 30 min (\%) & 88.7 & 89.7 & 91.7 \\
& Voltage at first (V) & 3.777 & 3.779 & 3.783 \\
& Voltage at 30 min (V) & 3.939 & 3.951 & 3.972 \\
\hline \multirow{5}{*}{ With Equalization } & Initial SOC (\%) & 72 & 73 & 75 \\
& SOC at 20 min (\%) & 83.4 & 83.4 & 89 \\
& SOC at 30 min (\%) & 89 & 89 & 3.783 \\
& Voltage at first (V) & 3.777 & 3.779 & 3.954 \\
\hline & Voltage at 30 min (V) & 3.950 & 3.951 & \\
\hline
\end{tabular}

The balancing efficiency is the ratio between the change of battery capacity after balancing with and without equalization. Since the battery considered in the case study above has only three cells, the 
change of battery capacity after balancing consists of the sum of the relevant changes at each of the three battery cells, that is:

$$
\eta=\frac{\sum_{i=1}^{3} C_{b a t, i}\left(S O C_{e b, i}-S O C_{s, i}\right)}{\sum_{i=1}^{3} C_{b a t, i}\left(S O C_{e, i}-S O C_{s, i}\right)}
$$

where $C_{b a t, i}$ is the capacity of cell $i$. It can be observed that the balancing is finished at about $20 \mathrm{~min}$, so we can take the data at $20 \mathrm{~min}$ as the balanced results. $S O C_{e b, i}$ and $S O C_{e, i}$ is the SOC at $20 \mathrm{~min}$ with and without equalization, respectively. $S O C_{s, i}$ is the initial SOC of cell $i$.

Through above graphs and table, it can be concluded that the balance circuit of the topology can achieve battery equalization. Compared with [13,19], whose balancing currents are $1.725 \mathrm{~A}$ and $1.5 \mathrm{~A}$, this balancing scheme has the advantage to maintain higher balancing current which is about $1.8 \mathrm{~A}$. It also achieves the efficiency around $89 \%$ which is higher than the $80 \%$ efficiency in [19] and $80.4 \%$ in [20]. Furthermore, it can be observed from Figures 15 and 16 that this topology can achieve zero voltage turn off and zero current turn on, thus switching losses will be reduced against those [22-26] where soft switching cannot be achieved.

\section{Conclusions}

Though the equalization topologies based on transformers have the advantages of high balancing current and efficiency, they have the disadvantage of switching losses. A new transformer equalization topology with a LCD absorbing circuit and the corresponding balance control strategy are proposed to solve this problem. The feasibility of the equalization scheme is verified by simulations and experiments. The experiment shows that the equalization can be achieved at about $1.8 \mathrm{~A}$ balancing current and $89 \%$ efficiency. A comparative study is made and from the power tube voltage/current waveforms, it is found that soft switching can be realized by the topology proposed here, therefore switching losses are significantly reduced. Hence the topology proposed in this paper can achieve equalization, maintain the advantages of high balancing current and efficiency, and reduce switching losses. As a future work, this equalization scheme will be further tested for potential implementation on the battery packs of JAC Electric Vehicles.

Acknowledgments: This work was supported by National Natural Science Foundation of China (61603120) and National Natural Science Foundation of China (51607052).

Author Contributions: Xintian Liu helped to guide many professional problems of English paper writing. Yafei Sun performed the data analysis and wrote the manuscript. Yao He contributed to analysis and manuscript preparation. Xinxin Zheng, Guojian Zeng, Jiangfeng Zhang revised the manuscript.

Conflicts of Interest: The authors declare no conflict of interest. The founding sponsors had no role in the design of the study; in the collection, analyses or interpretation of data; in the writing of the manuscript; nor in the decision to publish the results.

\section{References}

1. Daowd, B.; Antoine, M.; Omar, N.; Lataire, P.; Bossche, P.V.E.; Mierlo, J.V. Battery Management System-Balancing Modularization Based on a Single Switched Capacitor and Bi-Directional DC/DC Converter with the Auxiliary Battery. Energies 2014, 7, 2897-2937. [CrossRef]

2. Fajri, P.; Ferdowsi, M.; Lotfi, N.; Landers, R. Development of an Educational Small-Scale Hybrid Electric Vehicle (HEV) Setup. IEEE Intell. Transp. Syst. Mag. 2016, 8, 8-21. [CrossRef]

3. Guo, X.; Kang, L.; Huang, Z.; Yao, Y.; Yang, H. Research on a Novel Power Inductor-Based Bidirectional Lossless Equalization Circuit for Series-Connected Battery Packs. Energies 2015, 8, 5555-5576. [CrossRef]

4. Hannan, M.A.; Hoque, M.M.; Peng, S.E.; Uddin, M.N. Lithium-Ion Battery Charge Equalization Algorithm for Electric Vehicle Applications. IEEE Trans. Ind. Appl. 2017, 53, 2541-2549. [CrossRef] 
5. Xie, C.; Xu, X.; Bujlo, P.; Shen, D.; Zhao, H.; Quan, S. Fuel Cell and Lithium Iron Phosphate Battery Hybrid Powertrain with an Ultracapacitor Bank Using Direct Parallel Structure. J. Power Sources 2015, 279, 487-494. [CrossRef]

6. Chunyan, X.; Chengjun, X.; Feng, J. Research and Design of the Balanced Technology of Battery Management System in Wind Power Generation. Int. J. Control Autom. 2016, 9, 453-462.

7. Lin, C.; Mu, H.; Zhao, L.; Cao, W. A New Data-Stream-Mining-Based Battery Equalization Method. Energies 2015, 8, 6543-6565. [CrossRef]

8. Feng, J.; Weiwen, D.; Jingshan, L. Performance Evaluation of Modularized Global Equalization System for Lithium-Ion Battery Packs. IEEE Robot. Autom. Soc. 2016, 13, 986-996.

9. Xie, C.; Ogden, J.M.; Quan, S.; Chen, Q. Optimal Power Management for Fuel Cell-Battery Full Hybrid Powertrain on a Test Station. Int. J. Electr. Power Energy Syst. 2013, 53, 307-320. [CrossRef]

10. Daowd, M.; Omar, N.; Van Den Bossche, P.; Van Mierlo, J. Passive and Active Battery Balancing Comparison based on MATLAB Simulation. In Proceedings of the 2011 IEEE Vehicle Power and Propulsion Conference (VPPC), Chicago, IL, USA, 6-9 September 2011.

11. Gacio, D.; Alonso, J.M.; Garcia, J.; Llera, D.G.; Cardesín, J. Study on Passive Self-Equalization of Parallel-Connected LED Strings. IEEE Trans. Ind. Appl. 2015, 51, 2536-2543. [CrossRef]

12. Gallardo-Lozano, J.; Romero-Cadaval, E.; Milanes-Montero, M.I.; Guerrero-Martinez, M.A. Battery Equalization Active Methods. J. Power Sources 2014, 246, 934-949. [CrossRef]

13. Tan, K.K.; Gao, F.; Loh, P.C.; Blaabjerg, F. Enhanced Buck-Boost Neutral-Point-Clamped Inverters with Simple Capacitive-Voltage Balancing. IEEE Trans. Ind. Appl. 2010, 46, 1021-1033.

14. Zheng, X.; Liu, X.; He, Y.; Zeng, G. Active Vehicle Battery Equalization Scheme in the Condition of Constant-Voltage/Current Charging and Discharging. IEEE Trans. Veh. Technol. 2017, 66, 3714-3723.

15. Ye, Y.; Cheng, K.W.E. An Automatic Switched-Capacitor Cell Balancing Circuit for Series-Connected Battery Strings. Energies 2016, 9, 138. [CrossRef]

16. Daowd, M.; Antoine, M.; Omar, N.; Van den Bossche, P.; Van Mierlo, J. Single Switched Capacitor Battery Balancing System Enhancements. Energies 2013, 4, 2149-2174. [CrossRef]

17. Ye, Y.; Cheng, K.W.E.; Fong, Y.C.; Xue, X.; Lin, J. Topology, Modeling, and Design of Switched-Capacitor-Based Cell Balancing Systems and Their Balancing Exploration. IEEE Trans. Power Electron. 2017, 32, 4444-4454. [CrossRef]

18. Shukla, A.; Ghosh, A.; Joshi, A. Flying-Capacitor-Based Chopper Circuit for DC Capacitor Voltage Balancing in Diode-Clamped Multilevel Inverter. IEEE Trans. Ind. Electron. 2010, 57, 2249-2261. [CrossRef]

19. Einhorn, M.; Guertlschmid, W.; Blochberger, T.; Kumpusch, R.; Permann, R.; Conte, F.V.; Kral, C.; Fleig, J. A Current Equalization Method for Serially Connected Battery Cells Using a Single Power Converter for Each Cell. IEEE Trans. Veh. Technol. 2011, 60, 4227-4237. [CrossRef]

20. Lee, K.M.; Lee, S.W.; Choi, Y.G.; Kang, B. Active Balancing of Li-Ion Battery Cells Using Transformer as Energy Carrier. IEEE Trans. Ind. Electron. 2017, 64, 1251-1257. [CrossRef]

21. Park, S.H.; Park, K.B.; Kim, H.S.; Moon, G.W.; Youn, M.J. Single-Magnetic Cell-to-Cell Charge Equalization Converter with Reduced Number of Transformer Windings. IEEE Trans. Power Electron. 2012, 27, 2900-2911. [CrossRef]

22. Wang, S.; Kang, L.; Guo, X.; Wang, Z.; Liu, M. A Novel Layered Bidirectional Equalizer Based on a Buck-Boost Converter for Series-Connected Battery Strings. Energies 2017, 10, 1011. [CrossRef]

23. Li, W.H.; Ran, F.; Ji, Y.; Qin, J.Q.; Xu, H. A Battery Equalizing Scheme Using Flyback Converter and PhotoMOS Switch. Electronics. In Electronics, Communications and Networks $V$; Lecture Notes in Electrical Engineering; Springer: Singapore, 2016; Volume 382, pp. 1-9.

24. Yarlagadda, S.; Hartley, T.T.; Husain, I. A Battery Management System Using an Active Charge Equalization Technique Based on a DC/DC Converter Topology. IEEE Trans. Ind. Appl. 2013, 49, 2720-2729. [CrossRef]

25. Chen, Y.; Liu, X.; Cui, Y.; Zou, J.; Yang, S. A Multiwinding Transformer Cell-to-Cell Active Equalization Method for Lithium-Ion Batteries with Reduced Number of Driving Circuits. IEEE Trans. Power Electron. 2016, 31, 4916-4929.

26. Li, S.; Mi, C.C.; Zhang, M. A High-Efficiency Active Battery-Balancing Circuit Using Multiwinding Transformer. IEEE Trans. Ind. Appl. 2013, 49, 198-207. [CrossRef] 
27. Milanovic, M.; Korelic, J.; Hren, A.; Mihalic, F.; Slibar, P. The RC-RCD Clamp Circuit for Fly-Back Converter. In Proceedings of the 2016 International Symposium on Computer, Consumer and Control (IS3C), Xi'an, China, 4-6 July 2016.

28. Ji, W.; Ran, F.; Ji, Y.; Lu, X.; Guo, A. A Low Cost Battery Equalizing Scheme with Buck-Boost and Series LC Converter Using Synchronous Phase-Shift Controller. IEICE Electron. Express 2017, 14, 20161166. [CrossRef]

29. Kang, J.S.; Kim, Y.H.; Youn, S.J.; Won, C.Y.; Jung, Y.C. Active Clamp Flyback Inverter Considering Leakage Inductance of Transformer for Photovoltaic AC Modules. In Proceedings of the Vehicle Power and Propulsion Conference (VPPC) 2012 IEEE, Seoul, Korea, 9-12 October 2012.

30. Kernighan, B.W.; Ritchie, D.M. The C Programming Language; Prentice Hall PTR: Upper Saddle River, NJ, USA, 2006.

31. Kim, J.H.; Shin, J.W.; Jeon, C.Y.; Cho, B.H. Screening Process of Li-Ion Series Battery Pack for Improved Voltage/SOC Balancing. In Proceedings of the 2010 International Power Electronics Conference (IPEC), Sapporo, Japan, 21-24 June 2010.

(C) 2017 by the authors. Licensee MDPI, Basel, Switzerland. This article is an open access article distributed under the terms and conditions of the Creative Commons Attribution (CC BY) license (http:/ / creativecommons.org/licenses/by/4.0/). 